\title{
Relação entre conteúdos das disciplinas de curso de odontologia e os ENADE 2004/2010
}

\author{
Luiz Roberto Augusto Noro \\ Angelo Giuseppe Roncalli \\ Maria Cristina dos Santos Medeiros \\ Bárbara Cássia de Santana Farias-Santos \\ Isabel Alves Gomes Pinheiro
}

Resumo: O Sistema Nacional de Avaliação do Ensino Superior tem como objetivo acompanhar os cursos de graduação, permitindo que adequações sejam realizadas, sendo um de seus componentes o Exame Nacional de Desempenho do Estudante (ENADE). O objetivo do estudo foi comparar as questões $\neg$ das provas dos ENADE 2004 e 2010 com os conteúdos das disciplinas do Curso de Odontologia da UFRN a partir da percepção de alunos concluintes e professores. Para consolidação das respostas as disciplinas foram identificadas a partir dos conteúdos previstos nas Diretrizes Curriculares Nacionais classificados em ciências básicas, saúde coletiva, propedêutica clínica e clínica odontológica. Observou-se desarticulação entre ciclo básico e ciclo profissionalizante, uma vez que os alunos sinalizaram nas respostas que não há coerência entre a extensa carga horária das disciplinas básicas e os conteúdos abordados sobre estas no ENADE. Uma das limitações para avanço nesta articulação é o isolamento destas disciplinas em Departamentos e Centros de Ciências sem articulação, os quais contribuem para a fragmentação do ensino em disciplinas isoladas e descontextualizadas, situação presente em várias instituições de ensino superior no Brasil. Para transformação desta situação é fundamental a autoavaliação constante que viabilize empoderamento aos atores diretamente envolvidos e interessados em um ensino superior de qualidade.

Palavras-chave: Avaliação Educacional. Currículo. Educação em Odontologia

Relations between contents of the dentistry courses and ENADE 2004/2010

Abstract: The National System of Evaluation of Higher Education has the objective of accompanying the undergraduate courses and to allow adjustments to be made. One of its components is the National Student Performance Exam (ENADE). The objective of the study was to compare the questions from the ENADE 2004 and 2010 tests with the contents of the subjects of the UFRN Dentistry Course, based on the perception of graduate students and teachers. To consolidate the answers, the disciplines were identified based on the contents of the National Curricular Guidelines classified as basic sciences, collective health, clinical propaedeutics and odontological clinics. There was disarticulation between the basic cycle and the vocational cycle, since the students indicated in the answers that there is no coherence between the extensive workload of the basic subjects and the contents covered about them in ENADE. One of the limitations for advancement on this articulation is the insularityof these disciplines in Departments and Centers of Sciences without articulation, which contribute to the fragmentation of teaching in isolated and decontextualized disciplines, present situation in several institutions of higher education in Brazil. In order to transform this situation, a constant self-assessment that empowers the actors directly involved and interested in quality higher education is fundamental.

Key words: Educational evaluation. Curriculum. Education in Odontology. ENADE. 


\section{Introdução}

O Sistema Nacional de Avaliação do Ensino Superior (SINAES), aprovado por meio da Lei $\mathrm{n}^{\circ} 10.861$, de 14 de abril de 2004 tem como objetivo principal acompanhar os cursos de graduação, permitindo que adequações sejam realizadas nos cursos buscando sua excelência (BRASIL, 2004). Implicou mudança na lógica da avaliação ao definir os eixos da avaliação institucional, a avaliação de cursos e a avaliação dos estudantes, eliminando o Provão e criando o ENADE - Exame Nacional de Desempenho dos Estudantes (BARREYRO; ROTHEN, 2014).

O Exame Nacional de Desempenho dos Estudantes (ENADE) procura ser diagnóstico, de forma que seus resultados permitem correção e superação das dificuldades, ao passo que o Exame Nacional de Cursos (PROVÃO) era aplicado uma única vez ao final do curso e isso não permitia correção e superação das dificuldades do estudante avaliado (LIMANA; BRITO, 2005).

O Exame Nacional de Desempenho do Estudante é aplicado a todos os alunos concluintes dos cursos de graduação das várias áreas de conhecimento, com intervalo de três anos entre os mesmos (BRASIL, 2004). A avaliação consiste em instrumento fundamental no processo de reconfiguração política, econômica, social e educacional das nações, surgindo como tema não apenas por sua importância no âmbito das instituições de ensino superior brasileiras, mas também pelas dúvidas de professores e alunos sobre os reais efeitos do Exame Nacional de Avaliação do Desempenho dos Estudantes para melhoria do processo ensino-aprendizagem (GURGEL, 2010).

O Exame Nacional de Desempenho dos Estudantes (ENADE) configura-se como instrumento de avaliação institucional a partir de uma prova com conteúdos que contemplam as Diretrizes Curriculares Nacionais dos cursos de graduação (BRITO, 2008). Deve servir, pois, como referência para as revisões curriculares e suas possíveis adequações.

A formulação das questões se propõe a englobar várias dimensões de modo a contemplar a aprendizagem durante o curso e não somente ao seu final, com base nas competências profissionais e formação geral, com ênfase nos temas transversais (VERHINE; DANTAS; SOARES, 2006). O exame é composto de 40 questões, sendo 10 da área de Conhecimentos Gerais e 30 da área de Conhecimentos Específicos. A prova consta de 5 questões abertas ( 2 de conhecimentos gerais e 3 de conhecimentos específicos) e 35 questões de múltipla escolha (BRITO, 2008). Os cursos de graduação em Odontologia foram avaliados nas edições de 2004, 2007 e 2010, tendo o Curso de Odontologia da Universidade 
Federal do Rio Grande do Norte (UFRN) obtido o conceito 5 (cinco) nas três edições (BRASIL, 2014).

O presente estudo teve como objetivo comparar as questões das provas dos ENADE 2004 e 2010 com os conteúdos ministrados nas disciplinas do Curso de Odontologia da UFRN a partir da percepção de alunos concluintes e professores, assim como comparar a distribuição da carga horária dos conteúdos no currículo com questões dos referidos exames.

\section{Metodologia}

O presente estudo configura-se como transversal analítico uma vez que buscou relacionar as abordagens atuais desenvolvidas no currículo do curso de Odontologia com os conteúdos abordados nos ENADE 2004 e 2010.

O currículo do curso de Odontologia da UFRN prevê carga horária total de 4350 horas, a ser integralizado em quatro anos e meio. Esta carga horária está dividida em 105 horas de atividades complementares, 105 horas de disciplinas optativas, 180 horas de estágio de campo, 60 horas de trabalho de conclusão de curso e 3900 horas de disciplinas obrigatórias (incluídas 465 horas de estágios intramuros). Das disciplinas obrigatórias, 2985 horas (33 disciplinas) são realizadas no âmbito do Departamento de Odontologia, ao passo que 915 horas (13 disciplinas) são ofertadas por outros 8 Departamentos da UFRN.

A população do presente estudo foi composta por professores lotados no Departamento de Odontologia e alunos concluintes do curso de Odontologia da UFRN no semestre 2011.2 A amostra final do estudo foi composta por 24 professores, coordenadores de disciplinas ofertadas no âmbito do Curso de Odontologia. Em relação aos alunos compuseram amostra intencional um total de 4 alunos identificados a partir de seu ótimo desempenho acadêmico ao longo do curso, assim como a destacada participação em atividades acadêmicas como monitoria, iniciação científica e projetos de extensão. A decisão de trabalhar com estudantes que se destacaram foi intencional, pois se compreende que estes alunos, a partir de seu potencial diferenciado, representariam a melhor contribuição do curso para o aprendizado dos alunos.

O primeiro passo da pesquisa foi localizar as provas realizadas nos ENADE 2004 e 2010 no website do INEP (BRASIL, 2014) e transcrever as questões de conhecimentos específicos para duas matrizes de análise.

A matriz I, composta de três campos, foi respondida pelos professores por meio virtual. As orientações para o preenchimento foram feitas ao longo de oficina pedagógica com o corpo docente, na qual os objetivos da pesquisa, assim 
como as possíveis dúvidas, foram esclarecidos pelos pesquisadores. O campo 1 da matriz era preenchido nas situações em que o professor identificava o conteúdo da questão do ENADE como componente principal na sua disciplina; o campo 2 nas situações em que o conteúdo configurava-se como componente secundário na disciplina e o campo 3 sinalizava a carga horária destinada aos conteúdos abordados na questão. Componente principal referia-se a conteúdos essencialmente desenvolvidos na disciplina e explicitados no plano de ensino da disciplina, ao passo que componente secundário era compreendido como conteúdo que apoiava o conteúdo principal da disciplina, sem ser especificamente desenvolvido pela disciplina, não necessitando, portanto, ser contemplado no plano de ensino da disciplina. Nas situações em que o professor não via relação da questão com sua disciplina, foi solicitado que deixasse o campo relativo à questão em branco.

A matriz I foi encaminhada para todos os professores do Departamento de Odontologia da UFRN, estabelecendo-se um prazo para devolutiva das respostas. Visando maior participação dos docentes, dois comunicados enfatizando a importância da devolutiva foram encaminhados ao longo do prazo estabelecido.

A matriz II foi respondida pelos alunos aos quais era solicitado preencherem dois campos, também relacionando os conteúdos com as disciplinas do currículo. No campo 1, o aluno sinalizava em quais disciplinas identificava conteúdos que contribuíssem para responder a questão de forma principal e secundária, na mesma lógica da matriz encaminhada aos professores, enquanto no campo 2, o aluno sinalizava se sentia-se capacitado para responder a questão. Da mesma forma que aos professores, os pesquisadores explicaram aos alunos a metodologia para preenchimento da matriz de análise, assim como apresentaram os objetivos da pesquisa.

Para consolidação das respostas, as disciplinas foram identificadas a partir dos conteúdos essenciais previstos nas Diretrizes Curriculares Nacionais dos cursos de graduação em Odontologia: (1) ciências biológicas e da saúde; (2) ciências humanas e sociais e (3) ciências odontológicas, incluindo propedêutica clínica, clínica odontológica e odontologia pediátrica (BRASIL, 2002). No presente estudo, por finalidade didática, esses conteúdos foram classificados em 4 áreas: (1) ciências básicas, (2) saúde coletiva, (3) propedêutica clínica e (4) clínica odontológica.

Após a devolução das matrizes preenchidas por professores (matriz I) e alunos (matriz II), foi construído banco de dados, sistematizado no programa Microsoft Office Excel 2013. Para essa sistematização, as respostas das matrizes preenchidas pelos professores foram transportadas para cada uma das questões 
do ENADE, sinalizando os componentes principais e secundários abordados em cada disciplina, além da carga horária destinada a cada questão, por diferentes disciplinas. Das matrizes respondidas pelos alunos da mesma forma, foram consideradas para a consolidação, todas as respostas sugeridas.

A partir do banco de dado foi realizada análise estatística descritiva das respostas, buscando identificar a distribuição das respostas de professores e alunos de acordo com componentes principais e secundários, assim como a porcentagem de carga horária utilizada para desenvolvimento dos conteúdos, em comparação ao exigido nas questões dos ENADE 2004 e 2010.

Num segundo momento, foi realizada análise estatística comparando as matrizes respondidas pelos professores e alunos, permitindo observar a coerência entre os dois atores principais do processo ensino-aprendizagem, dentro de um mesmo currículo.

\section{Resultados e Discussão}

Dos componentes curriculares do Curso de Odontologia da UFRN, 24 disciplinas obrigatórias e 2 disciplinas optativas devolveram as matrizes preenchidas. Todas elas pertenciam ao Departamento de Odontologia sendo 2 disciplinas da área de Ciências Básicas, 12 disciplinas da área de Clínica Odontológica, 3 disciplinas da área de Propedêutica Clínica e 7 disciplinas da área de Saúde Coletiva. Os dados fornecidos pelos professores permitiram identificar a distribuição dos conteúdos nas questões como componente principal e secundário, a carga horária destinada ao desenvolvimento desse conteúdo e a proporção desses conteúdos com a carga horária total, de acordo com as quatro áreas de conhecimento conforme observado na Tabela 1 .

\section{Tabela 1 - Número de questões, carga horária e porcentagem da carga horária total, de acordo com componente, por área de conhecimento, referidas pelos professores.}

\begin{tabular}{lllllll}
\hline \multirow{2}{*}{ Área } & \multicolumn{7}{c}{ Componente } & Principal & \multicolumn{5}{c}{ Secundário } \\
\cline { 2 - 7 } & Questões & $\mathrm{CH}$ & $\%$ & Questões & $\mathrm{CH}$ & $\%$ \\
\hline Básica & 3 & 6 & 8,0 & 6 & 9 & 12,0 \\
\hline Propedêutica & 18 & 65 & 36,1 & 5 & 11 & 6,1 \\
\hline Clínica & 63 & 189 & 24,2 & 80 & 160 & 20,5 \\
\hline Saúde Coletiva & 30 & 97 & 29,4 & 7 & 52 & 15,8 \\
\hline
\end{tabular}


Nota-se uma baixa quantidade de questões que teve disciplinas da área básica como componente principal, porém o que chama mais atenção é o fato de também serem poucas as questões que têm as ciências básicas como componente secundário já que essas disciplinas, de cunho estrutural, deveriam ser base e encaradas na condição de conhecimento prévio para grande parte das disciplinas da área profissionalizante e saúde coletiva. Os professores dessas disciplinas se empenham historicamente em adequar uma visão integrada entre diversas delas e "convencer os alunos" de que os conteúdos de suas disciplinas terão certamente uma aplicação prática em algum momento da carreira acadêmica e profissional (WANNMACHER, 2001).

O que se pode inferir sobre o resultado encontrado é a questão da desarticulação entre o ciclo básico e o profissionalizante, o qual tem sido amplamente discutido na área da saúde, sinalizando a necessidade da integração curricular como meta a ser efetivamente concretizada (MEIRA; KURGANT, 2009; TAVARES, 2003; CYRINO; TORALLES-PEREIRA, 2004).

Esta evidência reforça a visão de que os currículos dos cursos na área da saúde têm seu modelo historicamente organizado em disciplinas isoladas, desvinculadas da realidade, voltadas para uma formação tecnicista e para especialidades, não formando profissionais que atendam às necessidades de saúde da sociedade (LAZARINI; GOULART, 2013).

Todos os alunos participantes do estudo sinalizaram que saberiam responder a mais de $95 \%$ das questões. Quanto à análise em relação às áreas de conhecimento identificadas, para os alunos $7,5 \%$ das questões poderiam ser respondidas com elementos das ciências básicas, 23,1\% da saúde coletiva, 11,4 da propedêutica clínica e 58\% da clínica odontológica. Quando observamos a estrutura curricular atual observa-se que esta distribuição ocorre com 23,7\% da carga horária na área básica, $12,7 \%$ em saúde coletiva, $6 \%$ em propedêutica e 54\% na área clínica. Todas as áreas de conhecimento, com exceção da área básica, tiveram menor carga horária do que a ocorrência de questões com este conteúdo nestes ENADE (Figura 1).

É fundamental, portanto, repensar a articulação entre básico e profissionalizante, uma vez que os alunos demostraram em suas respostas que não há coerência entre a extensa carga horária utilizada para as disciplinas básicas do curso e os conteúdos abordados sobre essas no ENADE. Em contrapartida, quando se analisa o mesmo parâmetro para o ciclo profissionalizante, os alunos enxergam maior quantidade de conteúdos abordados nas questões em detrimento das ciências básicas, sendo equivalente a carga horária utilizada nestas disciplinas. Este fato provavelmente se deve à distância entre esses 
Figura 1 - Comparação entre a carga horária do currículo e o número de respostas referidas pelos alunos.

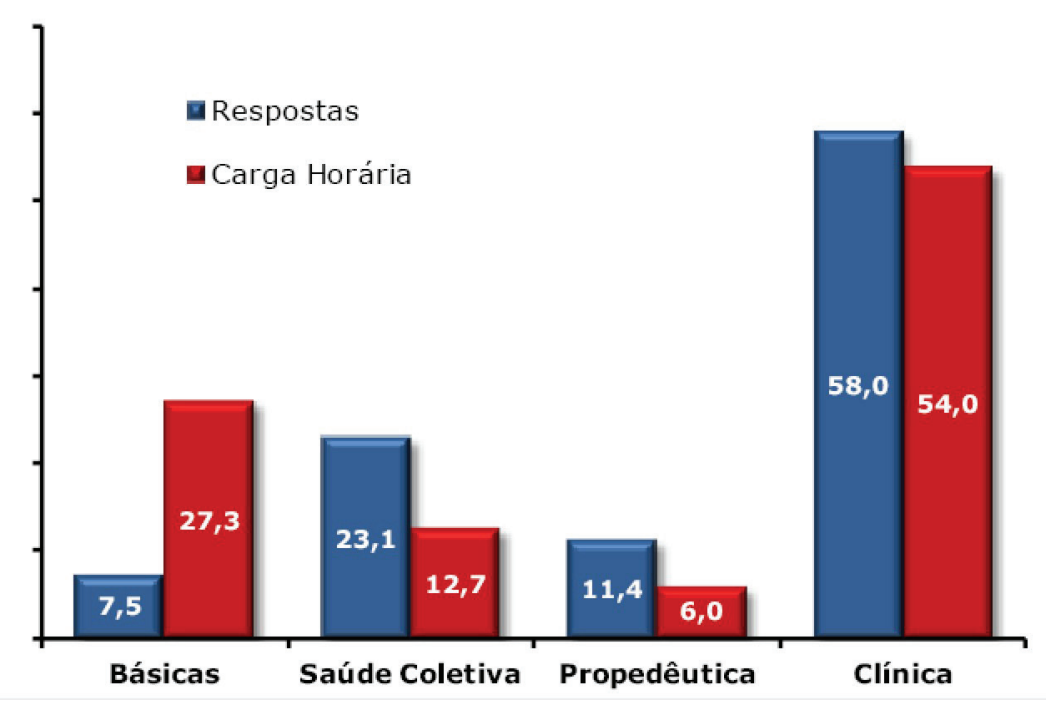

conhecimentos, contemplados no início do curso de forma fragmentada, não sendo por isso, identificados pelos alunos nem de maneira secundária. Somado a isso também se tem o viés de memória do aluno, já que esses conteúdos são ministrados, na maioria das vezes, de forma pontual e descontextualizados (CYRINO; TORALLES-PEREIRA, 2004).

Esse descompasso entre o que foi contemplado nos ENADE, que é um exame que avalia a forma como as DCN estão sendo contempladas no curso e as áreas de conhecimento sobre as quais os projetos pedagógicos são construídos, e o respondido por professores e alunos, demonstra a necessidade de reavaliar o atual projeto pedagógico do curso, assim como sinaliza a necessidade de investimento constante no desenvolvimento docente. Os projetos pedagógicos têm como principal característica a construção coletiva, buscando adequar os elementos presentes nas DCN no contexto ao qual se inserem, com objetivo de construir uma instituição de ensino superior aspirada pela sociedade (BRITO, 2008), que rompa com os modelos profissionais que surgem a partir da formação profissional em odontologia, que ainda são despolitizados e alheios aos diversos contextos sociais, uma vez que se sustentam no trabalho clínico-especializado (FINKLER; CAETANO; RAMOS, 2014), o que é reflexo da falta de compreensão das próprias DCN. 
É fundamental o desenvolvimento de uma visão sistêmica da formação, mediada por uma prática integradora, que valorize o enfoque problematizador e atividades acadêmicas que tenham como eixos a prática no contexto do trabalho em saúde e a inserção dos professores e alunos como sujeitos na produção contextualizada dos saberes, buscando a aproximação e interação entre diferentes áreas de conhecimento, projetos, atores e segmentos sociais (TAVARES, 2003; BATISTA, 2006).

Da mesma forma é fundamental que a integração do currículo faça parte do ideário do conjunto de professores, contemplando-se a perspectiva de formulação de um projeto no qual o mais importante é a aprendizagem contextualizada pelo aluno, do que a garantia do conhecimento específico de uma única disciplina ministrada pelo professor. Sem dúvida, a formação dos docentes na maioria dos cursos de pós-graduação e a prática odontológica, ainda fortemente baseada na ultraespecialização, contribuem decisivamente no apego do professor pela disciplina a qual "domina" e sente-se confortável em ministrar. Fica evidente, portanto que a incorporação de melhorias no processo educativo de estudantes e professores será fundamental para aumento da qualidade da Odontologia brasileira (GRAZZIOTIN-SOARES et al., 2011).

Quando comparada à atribuição de conteúdos necessários para responder as questões do ENADE entre alunos e professores, na maioria das disciplinas houve equilíbrio e concordância de ambos que os conteúdos eram importantes para responder as questões. Entretanto, casos específicos puderam ser observados (Figura 2).

A Clínica Integrada II chama atenção pelos seus aspectos positivos. Houve concordância de pontos de vista entre professores e alunos quanto aos conteúdos dessa disciplina e as questões do ENADE, o que evidencia o sucesso da integração dos conteúdos. É nesta disciplina que os alunos têm o primeiro contato com tal abordagem, além de ser também a primeira experiência mais próxima da prática odontológica propriamente dita, uma vez que são realizados os primeiros procedimentos clínicos que identificam classicamente a profissão. Nessa fase a segurança está relativamente mais consolidada e o aluno se sente mais confortável com a prática clínica.

A disciplina de Introdução à Odontologia, apesar da percepção do professor, não foi citada por nenhum aluno como essencial para responder as questões do ENADE. Isso pode ser explicado já que a disciplina não se enquadra como uma disciplina acadêmica convencional, uma vez que se configura muito mais como um primeiro contato do aluno ingressante com o Departamento de Odontologia, abordando temas referentes a aspectos da formação em Odontologia, 
Figura 2 - Grau de coerência entre as respostas dadas pelos alunos e professores com relação aos conteúdos das disciplinas e questões do ENADE

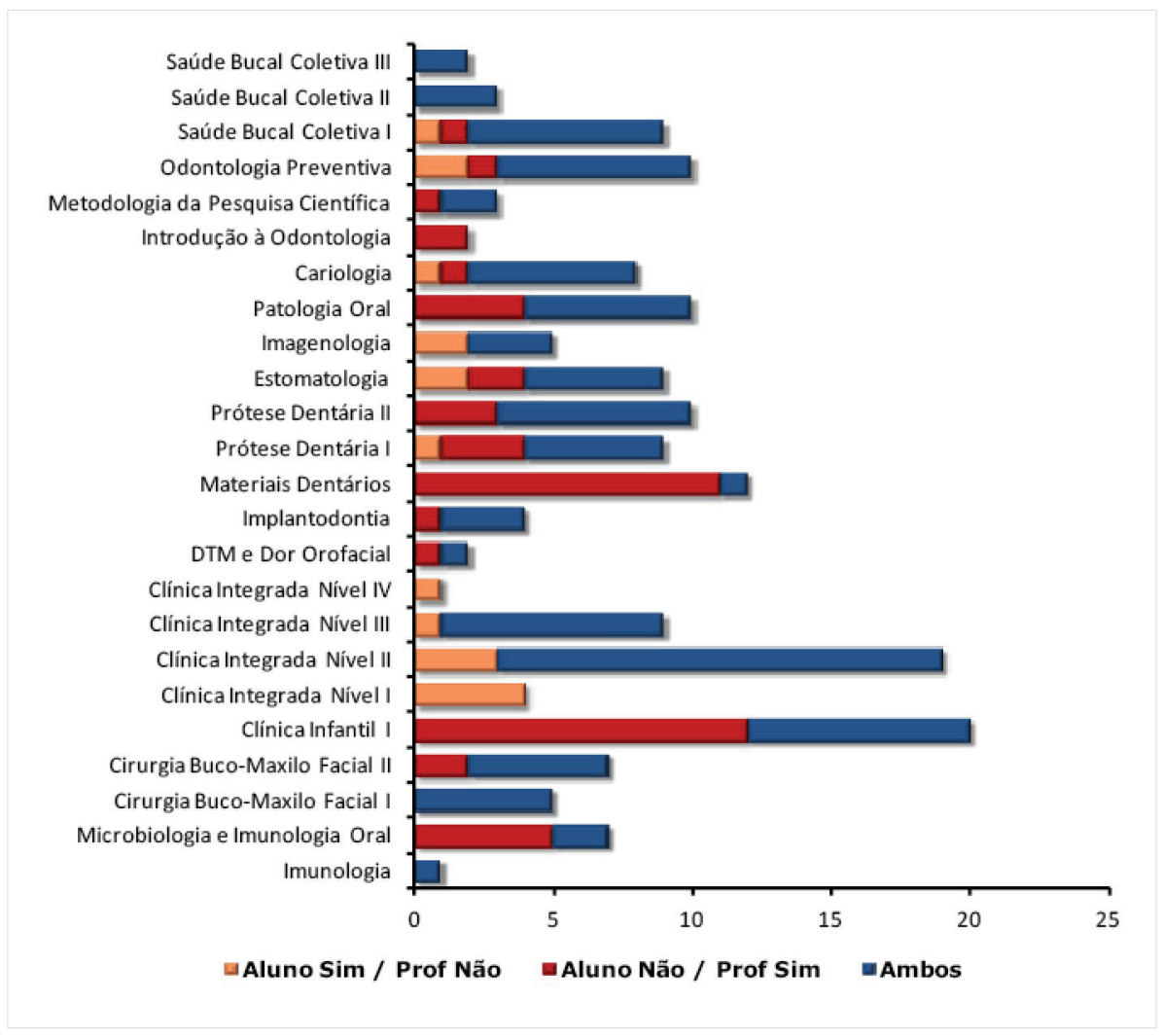

ao mercado de trabalho, ao universo da profissão, além de seus antecedentes históricos, o que não é abordado nas questões do ENADE.

Outra situação observada foi a da disciplina de Materiais Dentários, na qual o corpo docente atribuiu várias questões aos seus conteúdos, o que não foi sinalizado pelos alunos. A disciplina de Materiais Dentários é abordada isoladamente no quarto período do curso, sem relação direta com os cenários e atividades nos quais estes materiais serão efetivamente utilizados. Dessa forma, os alunos não conseguem associar sua teoria a prática clínica diária e provavelmente atribuem os conhecimentos que "deveriam ser aprendidos" nessa disciplina a outras disciplinas. Nos currículos integrados não há legitimidade 
na existência deste tipo de disciplina dada a maneira estanque como é ministrada. A proposta é que sua abordagem seja transversal, ao longo do curso, em articulação com as situações que exigem o referencial teórico das propriedades dos materiais associado a sua indicação clínica. Desta forma, a prática e a teoria estão aliadas a um contexto sólido, o que melhora a aprendizagem do aluno (CAMPOS et al., 2009).

Outra situação interessante é observada na Clínica Infantil. Muitos professores deste componente curricular identificaram conteúdos abordados nas questões do ENADE, o que não foi equivalente quando se analisa a visão dos alunos. Isso se deve ao fato de a Clínica Infantil abordar determinados conteúdos que já foram vistos de forma principal em outras disciplinas, como por exemplo, a cárie dentária, a doença periodontal, a utilização do flúor, entre outros. Aparentemente, os alunos só atribuem à Clínica Infantil as questões que trazem como sujeito o paciente pediátrico, mesmo que de forma secundária.

Nota-se o contrário com a disciplina de Clínica Integrada I em que apenas os alunos atribuíram seus conteúdos a resolução de questões e que os professores da disciplina não observaram. Isto pode ter acontecido pelo fato de haver neste semestre a articulação da Clínica Integrada I com outras disciplinas as quais os professores são os mesmos. Isso pode ter sugerido aos professores que o aprendizado ocorreu nestas disciplinas e não na Clínica I.

Situação muito preocupante aconteceu nas Clínicas Integradas $\mathrm{V} \mathrm{e} \mathrm{VI}\left(8^{\circ} \mathrm{e}\right.$ $9^{\circ}$ período do curso). Nenhuma questão dos ENADE analisados foi mencionada quer pelos alunos, quer pelos professores. Uma hipótese é que o professor assume como conteúdo dado apenas aquele ministrado em sala de aula, considerando a clínica somente como um local de prática, e não um efetivo e potente "lócus" de aprendizado (FAGUNDES; FRÓES, 2004). Uma possível explicação é que isso ocorre porque professores e alunos não identificam o espaço clínico como espaço de aprendizagem. Em especial nestes componentes curriculares, implantados na lógica de "estágios clínicos", aparentemente assume-se a pouca possibilidade de novos conhecimentos nesta fase do curso. Busca-se nesta fase do curso uma consolidação da prática profissional baseada no aperfeiçoamento da habilidade motora (necessária à prática clínica), com relativa autonomia do aluno (essencial neste momento do curso), mas com pouca reflexão sobre o processo formativo, pautado em metas de produção de procedimentos clínicos e desvalorização de aspectos relacionados à humanização das práticas e ao trabalho em equipe.

Isso sugere a necessidade de discutir a reorganização e aperfeiçoamento das clínicas em consonância com um sistema de acolhimento, articulado ao sistema 
de saúde, permitindo a hierarquização de procedimentos por meio do aumento da complexidade das situações clínicas (necessidades do paciente) articulado com o grau de conhecimento dos alunos ao longo dos períodos/semestres. Associado a isto deve haver uma articulação dessas atividades com a teoria, permitindo assim a aplicação efetiva dos conhecimentos, habilidades e atitudes adquiridos ao longo do curso (LEMOS; FONSECA, 2009).

De forma geral, tanto pelas respostas dos alunos como pela dos professores, todos os temas abordados pelo ENADE foram estudados no Curso de Odontologia da UFRN.

Apesar de existirem algumas críticas em relação ao ENADE, principalmente quanto à construção de instrumentos e indicadores, ele é um exame que não se limita a avaliar a aprendizagem e sim pretende ser um instrumento que contribua com o processo ensino-aprendizagem (GONTIJO et al., 2011). Tão pouco deve ser utilizado separado dos demais instrumentos do SINAES e nem ser considerado uma única nota separadamente (DIAS SOBRINHO, 2012).

A avaliação de um curso deve proporcionar melhoria da qualidade da oferta educacional, além de aperfeiçoar os processos acadêmicos e administrativos das universidades (FADEL; BALDANI, 2013). A avaliação deve ser formativa e, mais que a constatação de um estado, é uma interrogação sobre o processo de aprendizagem e formação, com objetivo de conhecer os avanços, superar dificuldades e atribuir sentido ao processo educativo (DIAS SOBRINHO, 2012).

\section{Conclusão}

O Curso de Odontologia da UFRN vem construindo caminhos em direção à organização da prática pedagógica buscando se apropriar cada vez mais aos elementos propostos pelas Diretrizes Curriculares Nacionais. No entanto, algumas lacunas persistem e indicam a necessidade de uma maior reflexão para correção de rumos e novos redirecionamentos.

Fica evidente a necessidade de melhorar a articulação entre o ciclo básico e o ciclo profissionalizante permitindo aprendizado mais contextualizado. $\mathrm{O}$ grande percentual de carga horária destinada às ciências básicas no Curso de Odontologia da UFRN, a baixa atribuição de conteúdos que tanto alunos como professores indicaram sendo das ciências básicas, além da pouca quantidade de questões dessas disciplinas elaboradas pelo ENADE indicam um descompasso tanto na forma como no conteúdo que elas estão sendo ministradas. Existem aprendizados fundamentais nos períodos iniciais (por isto chamado de "básicos”) que, entretanto, não podem ser materializados como disciplinas isoladas, 
responsáveis apenas de sua área específica de conhecimento, sem articulação com o contexto. Sem dúvida, uma das limitações para avanço nesta articulação é o isolamento dessas disciplinas em Departamentos isolados, em Centros de Ciências sem articulação, os quais contribuem para a fragmentação do ensino em disciplinas isoladas e descontextualizadas.

Especificamente em relação ao "lócus" de aprendizagem percebe-se que existem algumas incompreensões, interpretações inadequadas e conflitos em relação à articulação teoria e prática, nos quais ficam evidentes pelos resultados encontrados, que a sala de aula é o local de aprender a teoria e as clínicas e laboratórios locais de exercitar a prática. Essa dicotomia é impossível de ser imaginável quando se pretende que teoria e prática articulem-se a partir da ciência e do conhecimento reconstruídos na dimensão da ação-reflexão-ação.

Outra interpretação inadequada no âmbito da clínica é que este ambiente em um Curso de Odontologia tem como grande missão o aprendizado técnico do aluno, deixando de compreender o paciente como sujeito integral, com necessidades outras além de restabelecimento estético e funcional.

Neste sentido, é fundamental que as instituições de ensino superior ampliem o processo de reflexão, aproveitando-se dos instrumentos de avaliação e proporcionando espaços de discussão com alunos, professores, funcionários, egressos e toda a sociedade na perspectiva de promover transformações positivas na instituição.

A avaliação deve ser sempre uma ação transformadora, em especial na perspectiva da autoavaliação, estratégia fundamental para permitir empoderamento aos atores diretamente envolvidos e interessados em um ensino superior de qualidade, em especial consolidadas a partir das Diretrizes Curriculares Nacionais e a partir de princípios pedagógicos construtivistas.

\section{Referências}

BARREYRO, Gladys Beatriz; ROTHEN, José Carlos. Percurso da avaliação da educação superior nos Governos Lula. Educação e Pesquisa, São Paulo, v. 40, n. 1, p. 61-76, 2014.

BATISTA, Sylvia Helena Silva. A interdisciplinaridade no ensino médico. Revista Brasileira de Educação Médica, Rio de Janeiro, v. 30, n. 1, p. 39 46, jan./abr. 2006. 
BRASIL. Conselho Nacional de Educação Superior. Câmara de Educação Superior. Resolução CNE/CES n ${ }^{\circ}$ 3, de 19 de fevereiro de 2002. Institui Diretrizes Curriculares Nacionais do Curso de Graduação em Odontologia. 2002.

BRASIL. Lei $\mathrm{n}^{\circ} 10.861$, de 14 de abril de 2004. Institui o Sistema Nacional de Avaliação da educação Superior - SINAES e dá outras providências. Brasília, 2004.

BRASIL. Ministério da Educação. Instituto Nacional de Estudos e Pesquisas Educacionais Anísio Teixeira (INEP). Resultados do ENADE. Disponível em: $<$ http://portal.inep.gov.br/enade/resultados $\geq$. Acesso em: 13 mar. 2014.

BRITO, Márcia Regina Ferreira. O SINAES e o ENADE: da concepção à implantação. Avaliação, Campinas; Sorocaba, v. 13, n. 3, p. 841-850, nov. 2008.

CAMPOS, Célia Maria Silva; SOARES, Cássia Baldini; TRAPÉ, Carla Andréa; SILVA, Bárbara Ribeiro Buffete; SILVA, Tatiana Cristina. Articulação teoria-prática e processo ensino-aprendizagem em uma disciplina de Enfermagem em Saúde Coletiva. Revista da Escola de Enfermagem da USP, São Paulo, v. 43, n. 2, p. 1226-1231, dez. 2009.

CYRINO, Eliana Goldfarb; TORALLES-PEREIRA, Maria Lúcia. Trabalhando com estratégias de ensino-aprendizado por descoberta na área da saúde: a problematização e a aprendizagem baseada em problemas. Caderno de Saúde Pública, Rio de Janeiro, v. 20, n. 3, p. 780-788, jun. 2004.

DIAS SOBRINHO, José. Avaliação e transformações da educação superior brasileira (1995-2009): do provão ao SINAES. Avaliação, Campinas; Sorocaba, v. 15, n. 1, p. 195-224, mar. 2012.

FADEL, Cristina Berger; BALDANI, Márcia Helena. Percepções de formandos do curso de Odontologia sobre as Diretrizes Curriculares Nacionais. Trabalho, Educação e Saúde, Rio de Janeiro, v. 11, n. 2, p. 330354, maio/ago. 2013.

FAGUNDES, Norma Carapiá; FRÓES, Teresinha Burnham. Discutindo a relação entre espaço e aprendizagem na formação de profissionais de saúde. Interface - Comunicação, Saúde, Educação, Botucatu, v. 16, n. 9, p. 105114, set. 2004. 
FINKLER, Mirelle; CAETANO, João Carlos; RAMOS, Flávia Regina Souza. Modelos, mercado e poder: elementos do currículo oculto que se revelam na formação em odontologia. Trabalho, Educação e Saúde, Rio de Janeiro, v. 12, n. 2, maio/ago. 2014.

GONTIJO, Eliana Dias; SENNA, Maria Inês Barreiros; LIMA, Luciana Barreto de; DUCZMAL, Luiz Henrique. Cursos de graduação em medicina: uma análise a partir do SINAES. Revista Brasileira de Educação Médica, Rio de Janeiro, v. 35, n. 2, p. 209-218, jun. 2011.

GRAZZIOTIN-SOARES, Renata; REICHERT, Leandro de Azambuja; BUSATO, Adair Luiz Stefanello; MATTOS, Airton Pozo; BARBOSA, Alcebíades Nunes; FONTANELLA, Vania Regina Camargo. The evaluation of higher dental education in Brazil: a cross-sectional study. Revista Odonto Ciência, Porto Alegre, v. 26, n. 2, p. 121-25, 2011.

GURGEL, Carmesina Ribeiro. Análise do Exame Nacional de Desempenho dos Estudantes após o primeiro ciclo avaliativo das áreas de agrárias, saúde e serviço social do Estado do Piauí. Ensaio: Avaliação e Política Públicas em Educação, Rio de Janeiro, v. 18, n. 66, p. 85-104, jan./mar. 2010.

LAZARINI, Carlos Alberto; GOULART, Flávia Cristina. Integração básicoclínica no internato médico: Psiquiatria e Farmacologia. Revista Brasileira de Educação Médica, Rio de Janeiro, v. 37, n. 3, p. 343-349, jul./set. 2013.

LEMOS, Cristiane Lopes Simão; FONSECA Selva Guimarães. Saberes e práticas curriculares: um estudo de um curso superior na área da saúde. Interface - Comunicação, Saúde, Educação, Botucatu, v. 28, n. 13, p. 5769, mar. 2009.

LIMANA, Amir; BRITO, Márcia Regina Ferreira. O modelo de avaliação dinâmica e o desenvolvimento de competências: algumas considerações a respeito do ENADE. Avaliação, Campinas, v. 10, n. 2, p. 9-32, jun. 2005.

MEIRA, Maria Dyrce Dias; KURCGANT, Paulina. Avaliação de curso de graduação segundo egressos. Revista da Escola de Enfermagem da USP, São Paulo, v. 43, n. 2, p. 481-485, jun. 2009.

TAVARES, Cláudia Mara de Melo. Integração curricular no curso de graduação em enfermagem. Revista Brasileira de Enfermagem, Brasília, v. 56, n. 4, p. 401-404, jul./ago. 2003. 
VERHINE, Robert Evan; DANTAS, Lys Maria Vinhaes; SOARES, José Francisco. Do Provão ao ENADE: uma análise comparativa dos exames nacionais utilizados no Ensino Superior Brasileiro. Ensaio: Avaliação e Política Públicas em Educação, Rio de Janeiro, v. 14, n. 52, p. 291-310, jul./set. 2006.

WANNMACHER, Clóvis Milton Duval. Ensinando bioquímica para futuros médicos. Revista de Ensino de Bioquímica, São Paulo, v. 1, n. 1, p. 3-8, 2001.

Luiz Roberto Augusto Noro - Universidade Federal do Rio Grande do Norte Natal | RN | Brasil. Contato: luiz_noro@hotmail.com

Angelo Giuseppe Roncalli - Universidade Federal do Rio Grande do Norte Natal | RN| Brasil. Contato: roncalli@terra.com.br

Maria Cristina dos Santos Medeiros - Universidade Federal do Rio Grande do Norte | Natal | RN | Brasil. Contato: mcristinamedeiros@hotmail.com

Bárbara Cássia de Santana Farias-Santos - Universidade Federal do Rio Grande do Norte | Natal | RN | Brasil. Contato: bfarias0507@hotmail.com Isabel Alves Gomes Pinheiro - Universidade Federal do Rio Grande do Norte Natal | RN | Brasil. Contato: isabel-agp@hotmail.com

Artigo recebido em 25 de julho de 2015 e aprovado em 21 de dezembro de 2015. 
